\title{
Coronary intervention in diabetes: is it different
}

\author{
Amit Malviya, Animesh Mishra
}

Department of Cardiology, Northeastern Indira Gandhi Regional Institute of Health and Medical Sciences (NEIGRIHMS), Shillong, Meghalaya, India

\section{Correspondence to} Dr Amit Malviya, Department of Cardiology, Northeastern Indira Gandhi Regional Institute of Health and Medical Sciences, Shillong 793018, India; animesh.shillong@gmail. com

CrossMark

To cite: Malviya A, Mishra A. Heart Asia 2015;7:9-14. doi:10.1136/ heartasia-2014-010553

\section{INTRODUCTION}

Diabetics are at an increased risk of cardiovascular morbidity and mortality as a consequence of inherent metabolic abnormalities and comorbidities. Furthermore, these patients derive less benefit from the standard therapies of coronary artery disease (CAD); the unique pathophysiological response to arterial injury has a profound effect on outcomes of percutaneous coronary interventions (PCIs). However, as the technology, techniques and experience of operators in PCI are evolving, the understanding of revascularisation strategies and patterns of clinical practice are changing. In this review, we discuss specific issues related to cardiac intervention in diabetics.

\section{MAGNITUDE OF THE PROBLEM, PATHOPHYSIOLOGY AND MECHANISTIC INSIGHTS INTO ADVERSE OUTCOMES AFTER REVASCULARISATION}

Currently, diabetes affects $>180$ million people worldwide. In the current era of advanced medical therapy, improved medical facilities and medical infrastructure, the term myocardial infarction (MI) equivalent might not hold true. ${ }^{1}$ However, despite improved outcomes, the gradient of increased risk of mortality and morbidity as compared with nondiabetics persists throughout the spectrum of CAD. Diabetics constitutes around one quarter of patients undergoing revascularisation. Both types of revascularisation strategies have been evaluated extensively. Preoperative mortality, repeat revascularisation and long-term mortality are the issues of concern.

Diabetes is a metabolic disorder characterised by chronic hyperglycaemia and insulin resistance. Disturbed delicate balance of fibrinolytic system as well as abnormalities of platelet structure and function results (box 1) in a persistent prothrombotic milieu. $^{2}$ (A) Metabolic factors: Hyperglycaemia include endothelial dysfunction, vascular effects of advanced glycation end products, adverse effects of circulating free fatty acids and increased systemic inflammation. (B) Vascular anatomic characters: Diabetics have more frequent diffuse disease, higher prevalence of extensive $\mathrm{CAD}$, left main disease, multivessel disease and occlusions. The narrow calibred vessels are associated with impaired collateral development. (C) Adverse prothrombotic milieu and high atherosclerotic burden: Proteofibrinolytic system and platelet biology are unfavourably altered in diabetes and a state of platelet activation exists. Glycoprotein IIb/IIIa (GP $\mathrm{IIb} / \mathrm{IIIa}$ ) receptor density is high and increased thrombosis is an independent marker of adverse outcomes following PCI. Diabetics have a higher atherosclerotic burden and plaques, which are high risk and vulnerable to rupture.

\section{ADVERSE OUTCOMES AFTER CORONARY INTERVENTION IN DIABETICS \\ Balloon angioplasty and bare metal stent implantation \\ Procedure-related and in-hospital mortality}

Early studies had shown more procedural complications and in-hospital complications twofold higher in diabetics. However, the rate of angiographic success was same as non-diabetics. ${ }^{3}$ The complication rates fell in later studies, in-hospital mortality (1.9\% vs $4.3 \%)$, MI (1.0\% vs $7.4 \%)$, an in-hospital coronary artery bypass grafting (CABG) surgery $(0.8 \%$ vs $6.2 \%){ }^{4}$ Patients with diabetes poorly tolerate the ischemic complications of PCI. ${ }^{5}$ Renal dysfunction after PCI occurs more frequently in diabetics. ${ }^{6}$

Repeat revascularisation and long-term outcomes Initial data from the National Heart, Lung and Blood Institute reported restenosis rates exceeding $47 \%$ as compared with non-diabetics. ${ }^{7}$ An absolute $10 \%$ difference exists between patients with and without diabetes regarding repeat revascularisation. The restenotic process more often results in total occlusions, MI and ventricular dysfunction in diabetics than in non-diabetics. ${ }^{8}$

\section{Drug-eluting stents (DES)}

\section{Angiographic and clinical outcomes}

DESs altered both rate and type of restenosis compared with bare metal stents (BMSs) in diabetic population. However, the result was still inferior to that of non-diabetics. The TAXUS IV and SIRIUS trials provided enough evidence favouring DESs and showed reduction of target lesion revascularisation and restenosis rates to the tune of $65 \% .^{9}{ }^{10}$ Prevention of REStenosis with Tranilast and its Outcomes, the largest contemporary restenosis trial till date, showed that compared with non-diabetic patients, patients with diabetes were older, more often had comorbid health problems and had more complex culprit stenoses. But even after adjustment for these differences in baseline characteristics, diabetics still had higher 9-month rate of death (relative risk (RR) $1.87,95 \%$ CI 1.31 to 2.68 ), target vessel revascularisation (TVR; RR 1.27, 95\% CI 1.14 to 1.42 ), and the composite of death/MI and TVR (RR 1.26, 95\% CI 1.13 to 1.40$).{ }^{11}$ Diabetic status was also predictive of major adverse cardiac and cerebrovascular events (MACCE) and mortality in long term. ${ }^{12}{ }^{13}$ While DESs, compared to BMS are effective in reducing the need for repeat revascularisation but whether this translates into reduction in MI and lesser deaths is not clear. ${ }^{14}$

\section{DES compared with BMS in diabetes}

DESs reduce the rate of angiographic restenosis and need of repeat revascularisation in all patients and 


\section{Box 1 Abnormalities of platelet function}

- Increased thromboxane A2 synthesis/arachidonic acid metabolism

- Decreased nitric oxide and prostacyclin production

- Decreased antioxidant levels

- Increased expression of activation-dependent adhesion molecules (eg, glycoprotein IIb/IIla, P-selectin)

- Increased platelet microparticle formation

- Increased platelet turnover

diabetics too seem to derive benefit from DES as compared with BMS. Results of SIRIUS and TAXUS IV trials in the diabetic subgroup were encouraging. In DIABETES Trial ${ }^{15}$ target-lesion revascularisation at 9 months was significantly lower in the sirolimus-eluting stent (SES) group as compared with that in the BMS group $(6.3 \%$ vs $31.3 \%)$. However, in all these trial, diabetes was a significant predictor of target lesion revascularisation. Furthermore, whether reduced rates of restenosis translate into mortality benefit in the complex multivessel PCI in diabetics is unknown.

SESs compared with paclitaxel-eluting stents (PESs)

Three major trials were compared head to head, the SESs and PESs. ISAR-DIABETIS trial ${ }^{16}$ included patients with angina or a positive stress test and a native vessel culprit lesion (exclusion: ST-segment elevation MI, LMS disease and restenosis). Median angiographic follow-up was 196 days. The extent of in-segment late luminal loss was $0.24 \mathrm{~mm}$ greater in the paclitaxel-stent group than in the sirolimus-stent group $(\mathrm{p}=0.002)$. In the SIRTAX trial, ${ }^{17}$ the HR for MACCE was less in SES when compared with that in PES patients and this difference was more pronounced in diabetics. The REALITY trial was a prospective, randomised clinical study, designed to compare the safety and efficacy of the Cypher (SES) and the Taxus (PES). The primary endpoint was in-lesion binary restenosis rate by quantitative coronary angiography at 8 months post procedure. There was no difference between the groups with regard to the rate of binary angiographic in-lesion restenosis at 8 months. Angiographic parameters favoured a more robust inhibition of neointimal hyperplasia by the sirolimus-eluting Cypher stent. There were no differences between the groups with regard to in-lesion restenosis rates. There was a higher incidence of in-stent thrombosis ( $<30$ days) in Taxus-treated patients.

The resolute zotarolimus-eluting stent (ZES) and diabetes mellitus The resolute ZES is a new-generation DES consisting of a thinstrut cobalt alloy bare metal stent coated with a durable biostable polymer and the cell-cycle inhibitor zotarolimus. While DESs have been recommended for PCI in patients with diabetes, no DES prior to the resolute has been specifically indicated by the US Food and Drug Administration for use in this high-risk population based on 1-year target vessel failure (TVF) outcomes for on-label non-complex resolute DM patients against a performance goal derived from a meta-analysis of published literature (which included six trials with Cypher SES and Taxus PES) and pooled data for the endeavour ZES. The composite TVF endpoint included cardiac death, MI and TVR. At 1 year, the rate of TVF for the 878 non-complex diabetic resolute patients was $7.8 \%$, significantly lower than the performance goal of
$14.5 \%(\mathrm{p}=0.001)$. The recent data presented at the American College of Cardiology ${ }^{18}$ also report similar results.

Stent thrombosis after DES and disease progression

Insulin requiring diabetes is a strong and independent risk factor for probable and definite stent thrombosis with a risk twofold more than non-diabetics. ${ }^{19}{ }^{20}$ As discussed above, diabetics have a faster progression of native disease and appearance of new lesions is approximately $30 \%$ and attributed primarily to new lesions in the treated vessels. ${ }^{21}$

\section{PERCUTANEOUS REVASCULARISATION COMPARED WITH SURGICAL REVASCULARISATION (MULTIVESSEL PCI VS CABG)}

Surgical revascularisation is the recommended strategy in diabetics with multivessel disease, but recent trials have resulted in a changing paradigm for revascularisation strategies. Still, most randomised controlled trials have shown higher rates of repeat revascularisation procedures after PCI and survival advantage for CABG over PCI in patients with diabetes.

\section{Trials with long-term results}

The Emory Angioplasty versus Surgery Trial (EAST) compared a strategy of initial percutaneous transluminal coronary angioplasty (PTCA) versus CABG in patients with multivessel coronary heart disease. The 8 -year survival was greater in patients with diabetes who underwent CABG (75.5\%) compared with those who underwent PTCA (60.1\%; $p=0.23)$. Diabetic subjects who underwent PCI had a reduced survival rate $(60.1 \%$ vs $82.6 \% ; \mathrm{p}=0.02$ ). Repeat revascularisation occurred in $26.5 \%$ of the CABG-treated patients and in $65.3 \%$ of the PTCA-treated patients $(p=0.001)$ over a period of 8 years. ${ }^{22}$ Bypass Angioplasty Revascularization Investigation (BARI) investigators recently reported sustained survival benefit of CABG at 10 years, $71.0 \%$ for PTCA and $73.5 \%$ for CABG. However, treated DM patients randomised to CABG had higher survival than those randomised to PCI (PCI $45.5 \%$ vs CABG $57.8 \%$, $\mathrm{p}=0.025){ }^{23}$

\section{Registries with long-term result}

In contrast to results of EAST, BARI and $\mathrm{CABRI}^{24}$ which favoured CABG, the 20-year results of a European registry showed reduced survival rates in surgically treated patients. ${ }^{25}$

\section{CABG versus $\mathrm{PCl}$ with $\mathrm{BMS}$}

Table 1 summarises major randomised trials of multivessel PCI using stents versus $C A B G$, which included patients with diabetes. A recent meta-analysis ${ }^{26}$ included 10 major studies of revascularisation reported that in patients with diabetes (CABG, $\mathrm{n}=615$; PCI, $\mathrm{n}=618$ ), mortality was substantially lower in the CABG group than in the PCI group (HR 0.70, 0.56-0.87 95\% $\mathrm{CI}$ ); unlike non-diabetics where it was similar (HR 0.98, 0.86$1.12 ; \mathrm{p}=0.014)$.

\section{CABG versus $\mathrm{PCl}$ with $\mathrm{DES}$}

The SYNTAX trial was a landmark contemporary trial. In diabetics the 1-year composite MACCE rate was significantly higher after PES treatment compared with CABG treatment (RR 1.83). The RR of repeat revascularisation of PES over CABG was 3.18 in diabetics as compared with 1.94 in non-diabetics. Compared with CABG, diabetics had higher mortality after PES use in highly complex lesions, that is, SYNTAX score $>33$, (4.1\% vs $13.5 \%)$. Revascularisation with PES resulted in higher repeat revascularisation for both patients without diabetes 
Table 1 Trials comparing bare metal stents with CABG (results for diabetic subgroup)

\begin{tabular}{|c|c|c|c|c|c|}
\hline Trial & Period & Primary endpoint & Number of patients & Proportion of diabetics & Primary end point in diabetics \\
\hline ERACI $\|^{32}$ & 1996-1998 & MACE & 450 & $17.3 \%$ in both groups & $\begin{array}{l}\text { Thirty-day outcomes: similar in both } \mathrm{PCI} \text { and CABG } \\
\text { Five-year mortality: } \\
P C I \text { diabetic vs non-diabetic: } 10.0 \% \text { vs } 5.6 \% \text { ( } p=\mathrm{NS}) \\
\text { CABG diabetic vs non-diabetic } 10.2 \% \text { vs } 11.6 \% \text { ( } p=N S)\end{array}$ \\
\hline $\operatorname{sos}^{33}$ & 1996-1999 & Repeat revascularisation & 988 & $<6.0 \%$ & $\mathrm{n} / \mathrm{a}$ \\
\hline ARTS $^{34} 35$ & 1997-1998 & Freedom from MACCE at 1 year & 1205 & $\begin{array}{l}\text { PCI: } 19 \% \\
\text { CABG: } 16 \%\end{array}$ & $\begin{array}{l}\text { PCl: } 63.4 \% \\
\text { CABG: } 84.4 \% \\
p=0.001\end{array}$ \\
\hline AWESOME $^{36}$ & $1996-2000$ & Survival at 3 and 5 years & 454 randomised group & $32 \%$ in randomised group & $\begin{array}{l}\text { Three-year survival: } 72 \% \text { vs } 81 \% \text { ( } p=\text { NS) } \\
\text { Five-year freedom from repeat revascularisation/unstable } \\
\text { angina: CABG: } 54 \% \text { vs PCl: } 49 \%\end{array}$ \\
\hline
\end{tabular}

ARTS, Arterial Revascularization Therapies Study; CABG, coronary artery bypass grafting; MACCE, major adverse cardiac and cerebrovascular events; PCl, percutaneous coronary interventions.

(5.7\% vs $11.1 \%)$ and patients with diabetes (6.4\% vs $20.3 \%)$. The authors concluded that CABG remained the standard of care in patients of diabetes with left main or triple vessel disease. Table 2 summarises other contemporary trials. Arterial Revascularization Therapies Study-Part $\mathrm{II}^{27}$ was a major trial which concluded that PCI using SES was safer and more efficacious than using BMS in both diabetic and non-diabetics and was a valuable alternative to CABG in patients with diabetes as well. FREEDOM was a landmark trial asserted that CABG scores over PCI with DESs in patients with diabetes (all-cause mortality and MI). CABG was better, regardless of SYNTAX score, number of diseased vessels, ejection fraction, race or sex of the patient.

\section{Revascularisation versus medical therapy}

In the BARI 2D trial, the rates of death from any cause did not differ significantly between the revascularisation group and the medical therapy group. Prompt revascularisation significantly reduced major cardiovascular events, as compared with intensive medical therapy, among patients who were selected to undergo CABG largely because of a reduction in MI events. The COURAGE Trial also showed that PCI with optimal medical therapy was no better than optimal medical therapy alone for patients with stable CAD in diabetics and non-diabetics.

\section{IMPROVING OUTCOMES OF PCI IN DIABETICS Management of hyperglycaemia after CABG or $\mathrm{PCI}$ in patients with diabetes}

It is proposed that the strict control of hyperglycaemia immediate postoperative period may have beneficial effect on myocardial energetic. Indirect support for this concept came from studies in critically ill patients with diabetes. No specific studies are available to address this issue and no trial has shown improved PCI outcome after ST-segment-elevation myocardial infarction with the administration of insulin or glucose insulin potassium.

\section{Antiplatelet agents}

GP IIb/IIIa receptor antagonists have assumed an important place and provided improved outcomes after PCI in diabetics. A pooled analysis from three trials $(n=1462)$ investigating the use of the GP IIb/IIIa inhibitor, abciximab with PCI in patients with diabetes showed a $2 \%$ absolute mortality reduction $(4.5 \%$ vs $2.5 \%, \mathrm{p}=0.03$ ) at 1 year. $^{28}$ In recent meta-analysis of six trials of various GP IIb/IIIa inhibitors in acute coronary syndromes, mortality benefit was greater in patients with diabetes $(n=1279)$ who underwent PCI during the index hospitalisation
(4.0\% vs $1.2 \%, p=0.002)$. Contemporary PCI guidelines recommend GP IIb/IIIa inhibitors in patients with unstable CAD and in elective PCI patients with risk factors, such as diabetes. However, ISAR-SWEET trial did not report significant impact of abciximab on the risk of death and MI in patients with diabetes undergoing PCI, but abciximab reduced the risk of restenosis in patients with diabetes receiving BMS.

\section{Bioabsorbable stents}

After intense preclinical research, there has been a revolutionary advance that of bioresorbable vascular scaffolds (BVSs), which are designed to provide temporary radial support to the vessel, to facilitate administration of antiproliferative drugs and to promote recovery of the artery's normal structure and physiological function by gradual removal of the scaffolding through a process of biodegradation. BVSs have several advantages, including physiological recovery of the vessel, reduced stent thrombosis and need for antiplatelet therapy, fewer constraints on future interventions in the vessel and its collaterals and the possibility of using non-invasive diagnostic exams, particularly CT angiography. One-year clinical outcomes of patients with diabetes treated with everolimus-eluting BVS, a pooled analysis of the ABSORB and the SPIRIT trial, patients with diabetes treated with the BVS showed similar rates of device-oriented composite endpoint compared with non-diabetic patients treated with the BVS and patients with diabetes treated with everolimus-eluting metal stents (EESs). There were no differences in the incidence of definite or probable scaffold/stent thrombosis $(0.7 \%$ for both diabetic and non-diabetic patients with the BVS; $1.0 \%$ for patients with diabetes with the BVS vs $1.7 \%$ for patients with diabetes with EES in the matched study group).

\section{PRIMARY PCI IN DIABETICS}

Patients with diabetes more often present with late and with congestive heart failure, after a ST elevation MI. CABG is usually done in cases with mechanical complications or failed PCI. PCI is more effective than fibrinolytic therapy. Studies comparing fibrinolytic therapy with primary angioplasty with or without use of GP IIb/IIIa report better short- and long-term outcomes with primary PCI in diabetics. In a recent study of 6315 patients (14\% diabetics), 30-day mortality (9.4\% vs 5.9\%, $\mathrm{p}=0.001)$ was higher in patients with diabetes. ${ }^{29}$ Mortality was lower after primary PCI compared with fibrinolysis in both patients with diabetes (unadjusted OR, 0.49, 95\% CI 0.31 to $0.79, \mathrm{p}=0.004$ ) and without diabetes (unadjusted OR 0.69, $95 \%$ CI 0.54 to $0.86, p=0.001)$. Recurrent infarction and stroke were also reduced after primary PCI in both patient 
Table 2 Trials comparing drug-eluting stent (DES) with CABG in diabetic subjects

\begin{tabular}{|c|c|c|c|c|}
\hline Trial & Patients & $\begin{array}{l}\text { Primary } \\
\text { endpoint }\end{array}$ & Intervention & Results \\
\hline ARTS $\|^{27}$ & $\begin{array}{l}\text { Diabetic patients treated with SES. } \\
\text { Multivessel disease that included treatment } \\
\text { of the left anterior descending artery and at } \\
\text { least one other significant lesion ( } 50 \% \\
\text { diameter stenosis) in another major } \\
\text { epicardial coronary artery }\end{array}$ & MACCE & $\begin{array}{l}\text { Three-year clinical outcome was compared } \\
\text { with that of the historical diabetic and } \\
\text { non-diabetic arms of the randomised ARTS-I } \\
\text { trial }\end{array}$ & $\begin{array}{l}\text { In patients with diabetes, the incidence of } \\
\text { MACCE in ARTS-II was similar to that of both } \\
\text { PCI and CABG in ARTS-I. Conversely, the } \\
\text { incidence of death, CVA and MI was } \\
\text { significantly lower in ARTS-II than in ARTS-I } \\
\text { PCI (adjusted OR } 0.67,95 \% \text { CI } 0.27 \text { to } 1.65 \text { ) } \\
\text { and was similar to that of ARTS-I CABG }\end{array}$ \\
\hline CARDIA $^{37}$ & $\begin{array}{l}\text { Diabetes. Multivessel CAD (two or more } \\
\text { stenotic coronary or one in which PCI } \\
\text { suitability is unclear. } \\
\text { Consensus between a cardiologist and } \\
\text { surgeon that adequate revascularisation can } \\
\text { be achieved }\end{array}$ & $\begin{array}{l}\text { Death, non-fatal } \\
\text { MI or stroke } \\
\text { within } 1 \text { year }\end{array}$ & $\begin{array}{l}\text { Optimal PCI includes the use of aspirin, } \\
\text { clopidogrel, abciximab and SESs in all } \\
\text { patients. Modern CABG: defined as one or } \\
\text { more arterial conduit with a LIMA graft for } \\
\text { the anterior native vessels and off-pump } \\
\text { bypass at the surgical team's discretion }\end{array}$ & $\begin{array}{l}\text { Composite rate of death, MI and stroke: } \\
10.5 \% \text { in the CABG group and } 13.0 \% \text { in the } \\
\mathrm{PCl} \text { group (HR } 1.25, \mathrm{p}=0.39 \text { ), all-cause } \\
\text { mortality rates: } 3.2 \% \text { and } 3.2 \% \text {. Rates of } \\
\text { death, } \mathrm{MI} \text {, stroke or repeat revascularisation } \\
\text { were } 11.3 \% \text { and } 19.3 \% \text { (HR } 1.77, \mathrm{p}=0.02 \text { ). } \\
\text { CABG when compared with drug-eluting } \\
\text { stents ( } 69 \% \text { of patients), the primary outcome } \\
\text { rates were } 12.4 \% \text { and } 11.6 \% \text { (HR } 0.93 \text {, } \\
\mathrm{p}=0.82 \text { ). Could not prove } \mathrm{PCI} \text { non-inferiority }\end{array}$ \\
\hline PRECOMBAT $^{38}$ & $\begin{array}{l}\text { Inclusion: LMCA stenosis } \geq 50 \% \text { (visual } \\
\text { estimate); angina or documented ischaemia } \\
\text { amenable to both PCI or CABG; lesions } \\
\text { outside LMCA amenable to both PCI or } \\
\text { CABG. Exclusion: previous PCI } \\
\text { ( } \geq 12 \text { months); previous LMCA PCl; previous } \\
\text { CABG; LVEF } \leq 20 \% \text {; NYHA heart failure } \\
\text { class III or IV }\end{array}$ & $\begin{array}{l}\text { All-cause } \\
\text { mortality, MI } \\
\text { and stroke at } 2 \\
\text { years }\end{array}$ & $\begin{array}{l}\text { Randomisation CABG vs PCI ( } 30 \% \\
\text { diabetics) }\end{array}$ & $\begin{array}{l}\text { Primary end point: } 36 \text { patients in the } \mathrm{PCl} \\
\text { group as compared with } 24 \text { in the CABG } \\
\text { group (cumulative event rate, } 12.2 \% \text { vs } 8.1 \% \text {; } \\
\text { hazard ratio with } \mathrm{PCl}, 1.50 ; 95 \% \mathrm{Cl} 0.90 \text { to } \\
2.52 ; \mathrm{p}=0.12 \text { ). } \\
\text { Ischaemia-driven target-vessel } \\
\text { revascularisation: } 26 \text { patients in the } \mathrm{PCl} \text { group } \\
\text { as compared with } 12 \text { patients in the CABG } \\
\text { group (cumulative event rate, } 9.0 \% \text { vs } 4.2 \% \text {; } \\
\text { HR, } 2.18 ; 95 \% \mathrm{Cl} 1.10 \text { to } 4.32 ; \mathrm{p}=0.02 \text { ) }\end{array}$ \\
\hline FREEDOM $^{39}$ & $\begin{array}{l}\text { Diabetes. Multivessel CAD (two or more } \\
\text { lesions in major arteries), amenable to } \\
\text { either } \mathrm{PCI} \text { with DES or surgical } \\
\text { revascularisation. }\end{array}$ & $\begin{array}{l}\text { All-cause } \\
\text { mortality, MI } \\
\text { and stroke }\end{array}$ & $\begin{array}{l}\text { Compared multivessel stenting using SESs } \\
\text { with CABG superiority trial }\end{array}$ & $\begin{array}{l}\text { Primary composite end point: } \mathrm{PCl} 26.6 \% \text { vs } \\
\text { CABG } 18.7 \% \text {, } \mathrm{p} \text { value }=0.005 \\
\text { Death from any cause: } \mathrm{PCl} 16.3 \% \text { vs CABG } \\
10.9 \%, \mathrm{p} \text { value }=0.049 \\
\text { Myocardial infarction: } \mathrm{PCI} 13.9 \% \text { vs CABG } \\
6.0 \%, \mathrm{p} \text { value }<0.001 \\
\text { Stroke: } \mathrm{PCl} 2.4 \% \text { vs CABG } 5.2 \%, \mathrm{p} \\
\text { value }=0.03 \\
\text { Cardiovascular death: } \mathrm{PCI} 10.9 \% \text { vs CABG } \\
6.8 \%, \mathrm{p} \text { value }=0.12\end{array}$ \\
\hline
\end{tabular}

ARTS, Arterial Revascularization Therapies Study; CABG, coronary artery bypass grafting; CAD, coronary artery disease; CVA, cerebrovascular accident; LVEF, left ventricular ejection fraction; MACCE, major adverse cardiac and cerebrovascular events; MI, myocardial infarction; NYHA, New York Heart Association; PCl, percutaneous coronary interventions; SES, sirolimus-eluting stent.

groups. After multivariable analysis, primary PCI was associated with decreased 30-day mortality in patients with and without diabetes, with a point estimate of greater benefit in patients with diabetes. In non-ST MI, patients with acute coronary syndrome, there is no interaction between the effect of myocardial revascularisation and diabetic status. ${ }^{30}$ However, an early invasive strategy was associated with improved outcomes; in TACTICS-TIMI 18 , the benefit in patients with diabetes was greater than in non-diabetics.

\section{OUTCOMES IN INSULIN REQUIRING VERSUS NON-INSULIN REQUIRING DIABETES}

The issue of adverse outcomes in patients with insulin requiring diabetes (IRDM) versus those who are non-insulin requiring diabetes is far less than resolved. However, the published data indicate that short-term and mid-term outcomes may be worse in IRDM population. In a large, real-world multicenter registry of diabetic population from Italy, the use of DES was associated with a moderate reduction in the 2 -year risk of TVR, a benefit that was limited to non-insulin-dependent diabetic patients.

In the TRUE Study which evaluated clinical impact of the Taxus stent in non-insulin-requiring vs insulin-requiring diabetics, the 1 -month MACE rate was similar $(p=0.4)$ between the two groups, $3 \%$ vs $5 \%$. At 7 months, the MACE rate was significantly $(\mathrm{p}=0.001)$ lower in the group of diabetics on oral agents $(8.5 \%)$ than in insulin-requiring diabetics $(25.3 \%)$. This difference was constant $(\mathrm{p}<0.01$ for all) across deaths $(0 \%$ vs $8 \%)$, TVR $(8.4 \%$ vs $20.7 \%)$ and TLR $(3.1 \%$ vs $14.6 \%)$, while the rate of MI was similar $(5.3 \%$ vs $4.8 \%, \mathrm{p}=0.7)$. Further studies are required to evaluate the long-term effects.

\section{CONTEMPORARY GUIDELINES AND APPROACH TO REVASCULARISATION IN DIABETICS}

Contemporary PCI guidelines ${ }^{31}$ emphasise the long-term survival benefit of CABG over PCI in diabetics with multivessel disease. However, individual clinician judgment on the revascularisation strategy remains an important decisive factor. Although PCIs with DES have narrowed the gap with surgery, the effectiveness of PCI in CABG-eligible diabetic patients with stable multivessel disease is still not clear. Primary PCI is preferred over fibrinolysis if it can be performed within recommended time frame (class I, level of evidence-a). The use of DES is recommended to reduce restenosis and repeat TVR (class I, level of evidence-a). CABG should be considered when the extent of the CAD justifies a surgical approach (especially MVD), and the patient's risk profile is acceptable (class II, level of evidence-a). Figure 1 outlines an approach to choice of revascularisation in diabetics with multivessel CAD. 
Figure 1 Revascularisation algorithm in diabetics. CABG, coronary artery bypass grafting; $C A D$, coronary artery disease; LAD, left anterior descending artery; OMT, optimal medical therapy; $\mathrm{PCl}$, percutaneous coronary intervention.

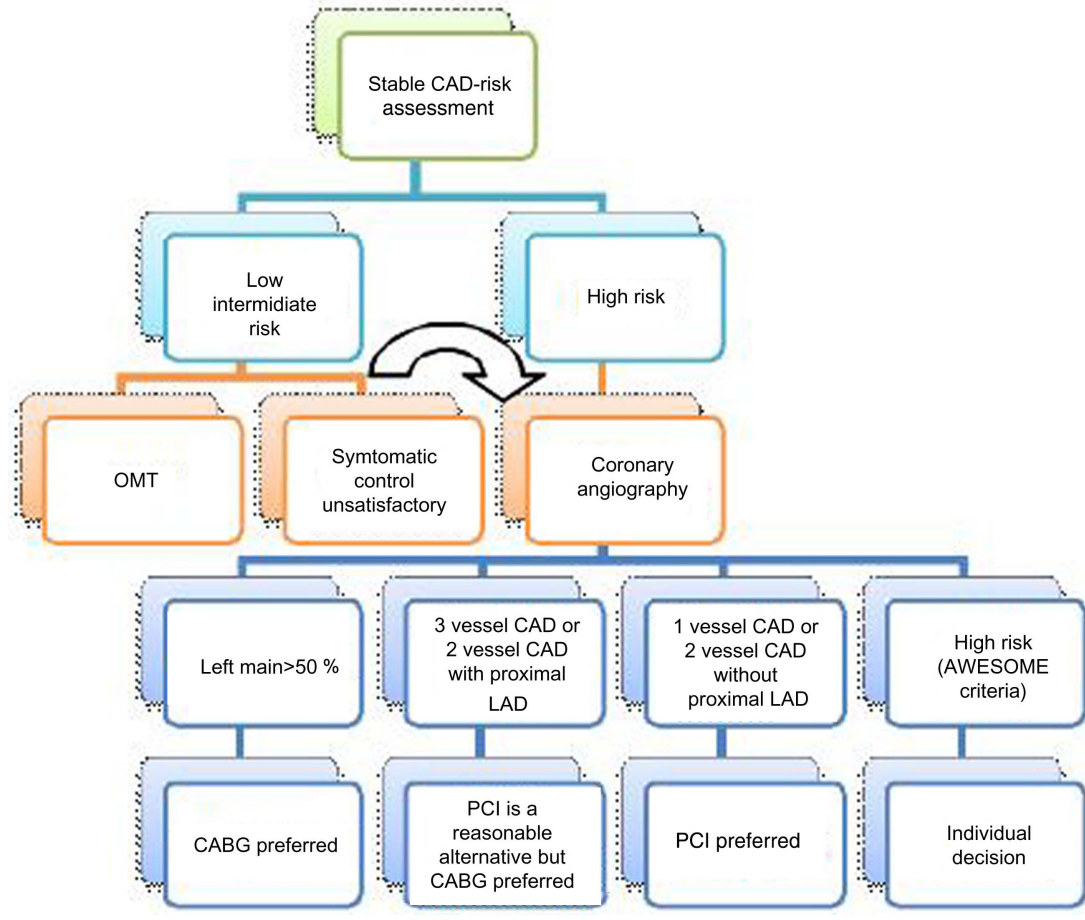

\section{CONCLUSION}

The expanding diabetic population and burden of CAD-related mortality and morbidity mandates a clear perspective in optimising the management of such patients, especially mode of myocardial revascularisation. This becomes even more important in view of the multiple adverse pathophysiological and anatomic characteristics and unique response to arterial injury which confer a relatively poor prognosis and worse outcome after revascularisation procedures. Several early studies comparing CABG surgery versus balloon-only PCI or BMS in subgroups of patients with diabetes with multivessel CAD demonstrated a survival advantage and less repeat revascularisation procedures with an initial surgical strategy. Recent advances in technique use of DES and progress in medical therapy appears to bridge the gap and have made PCI a viable alternative to CABG. Currently, mortality after PCI is comparable with that after $\mathrm{CABG}$, but the need for subsequent revascularisation is greater after PCI. Thus the revascularisation strategy should be individualised based on patient profile, anatomic characteristics of lesions. In general, it is a good idea to have a Heart Team Approach which involves combined assessments by primary physician, interventional cardiologists and cardiac surgeons, also taking into account the patient preference.

Contributors In relation to our manuscript, we declare that the authors were actively involved in the drafting, revision and final approval of the manuscript, hence we are accountable for all aspects of the work in ensuring that questions related to the accuracy or integrity of any part of the work are appropriately investigated and resolved.

Competing interests None.

Provenance and peer review Not commissioned; externally peer reviewed.

\section{REFERENCES}

1 Patel A, MacMahon S, Chalmers J, et al. Intensive blood glucose control and vascular outcomes in patients with type 2 diabetes. N Engl J Med 2008;358:2560.

2 Mathewkutty S, McGuire DK. Platelet perturbations in diabetes: implications for cardiovascular disease risk and treatment. Expert Rev Cardiovasc Ther 2009;7:541.
3 Kip KE, Faxon DP, Detre KM, et al. Coronary angioplasty in diabetic patients. The National Heart, Lung, and Blood Institute Percutaneous Transluminal Coronary Angioplasty Registry. Circulation 1996;94:1818-25.

4 Freeman AM, Abbott JD, Jacobs AK, et al. Marked improvements in outcomes of contemporary percutaneous coronary intervention in patients with diabetes mellitus. J Interv Cardiol 2006;19:475-82.

5 Goldberg S, Savage MP, Fischman DL. The interventional cardiologist and the diabetic patient. Have we pushed the envelope too far or not far enough? [editorial; comment]. Circulation 1996;94:1804-6.

6 Bartholomew BA, Harjai KJ, Dukkipati S, et al. Impact of nephropathy after percutaneous coronary intervention and a method for risk stratification. Am J Cardiol 2004;93:1515-19.

7 Holmes DJ, Vietstra R, Smith $H$, et al. Restenosis after percutanous transluminal coronary angioplasty (PTCA): a report from the PTCA Registry of the National Heart, Lung, and Blood Institute. Am J Cardiol 1984;53:77C-81C.

8 Mak KH, Faxon DP. Clinical studies on coronary revascularization in patients with type 2 diabetes. Eur Heart J 2003;24:1087-103.

9 Moussa I, Leon MB, Baim DS, et al. Impact of sirolimus-eluting stents on outcome in diabetic patients: a SIRIUS (SIRollmUS-coated Bx Velocity balloon-expandable stent in the treatment of patients with de novo coronary artery lesions) substudy. Circulation 2004;109:2273-8.

10 Hermiller JB, Raizner A, Cannon L, et al. Outcomes with the polymer-based paclitaxeleluting TAXUS stent in patients with diabetes mellitus: the TAXUS-IV trial. J Am Coll Cardiol 2005;45:1172-9.

11 Mathew V, Gersh BJ, Williams BA, et al. Outcomes in patients with diabetes mellitus undergoing percutaneous coronary intervention in the current era: a report from the Prevention of REStenosis with Tranilast and its Outcomes (PRESTO) Trial. Circulation 2004;109:476-80.

12 Laskey WK, Selzer F, Vlachos HA, et al. Comparison of in-hospital and one-year outcomes in patients with and without diabetes mellitus undergoing percutaneous catheter intervention (from the National Heart, Lung, and Blood Institute Dynamic Registry). Am J Cardiol 2002;90:1062-7.

13 Srinivas VS, Brooks MM, Detre KM, et al. Contemporary percutaneous coronary intervention versus balloon angioplasty for multivessel coronary artery disease: a comparison of the National Heart, Lung and Blood Institute Dynamic Registry and the Bypass Angioplasty Revascularization Investigation (BARI) study. Circulation 2002;106:1627-33.

14 Stettler C, Wandel S, Allemann S, et al. Outcomes associated with drug-eluting and bare-metal stents: a collaborative network meta-analysis. Lancet 2007;370:937.

15 Sabate M, Jimenez-Quevedo P, Angiolillo DJ, et al. Randomized comparison of sirolimus-eluting stent versus standard stent for percutaneous coronary revascularization in diabetic patients: the diabetes and sirolimus-eluting stent (DIABETES) trial. Circulation 2005;112:2175-83.

16 Dibra A, Kastrati A, Mehilli J, et al. Paclitaxel-eluting or sirolimuseluting stents to prevent restenosis in diabetic patients. N Engl J Med 2005;353:663-70. 
17 Windecker S, Remondino A, Eberli FR, et al. Sirolimus-eluting and paclitaxel-eluting stents for coronary revascularization. N Engl J Med 2005;353:653-62.

18 Yeung AC. The Resolute zotarolimus-eluting stent in patients with diabetes mellitus: two year outcomes. Presented at the American College of Cardiology, Chicago, 24-27 March 2012.

19 lakovou I, Schmidt T, Bonizzoni E, et al. Incidence, predictors, and outcome of thrombosis after successful implantation of drug-eluting stents. JAMA 2005:293:2126-30.

20 Wiviott SD, Braunwald E, Angiolillo DJ, et al. Greater clinical benefit of more intensive oral antiplatelet therapy with prasugrel in patients with diabetes mellitus in the trial to assess improvement in therapeutic outcomes by optimizing platelet inhibition with prasugrel-Thrombolysis in Myocardial Infarction 38. Circulation 2008; 118:1626-36.

21 Lemp GF, Vander Zwaag R, Hughes JP, et al. Association between the severity of diabetes mellitus and coronary arterial atherosclerosis. Am I Cardiol 1987;60:1015-19.

22 King SB, Kosinski AS, Guyton RA, et al. Eight-year mortality in the Emory Angioplasty versus Surgery Trial (EAST). J Am Coll Cardiol 2000;35:1116-21.

23 BARI Investigators. The final 10-year follow-up results from the BARI randomized trial. J Am Coll Cardiol 2007:49:1600-6.

24 Kurbaan AS, Bowker TJ, Isley CD, et al. Difference in the mortality of the CABRI diabetic and nondiabetic populations and its relation to coronary artery disease and the revascularization mode. Am J Cardiol 2001;87:947-50.

25 van Domburg RT, Foley DP, Breeman A, et al. Coronary artery bypass graft surgery and percutaneous transluminal coronary angioplasty: twenty-year clinical outcome. Eur Heart J 2002;23:543-9.

26 Hlatky MA, Boothroyd DB, Bravata DM, et al. Coronary artery bypass surgery compared with percutaneous coronary interventions for multivessel disease: a collaborative analysis of individual patient data from ten randomised trials. Lancet 2009;373:1190-7.

27 Daemen J, Kuck KH, Macaya C, et al. Multivessel coronary revascularization in patients with and without diabetes mellitus 3-year follow-up of the ARTS-II (Arterial Revascularization Therapies Study-Part II) trial. J Am Coll Cardiol 2008;52;1957-67.

28 Bhatt DL, Marso SP, Lincoff M, et al. Abciximab reduces mortality in diabetics following percutaneous coronary intervention. J AmColl Cardiol 2000;35:922-8.

29 Timmer JR, Ottervange JP, de Boer, MJ, et al; The Primary Coronary Angioplasty vs Thrombolysis-2 Trialists Collaborators Group. Primary percutaneous coronary intervention compared with fibrinolysis for myocardial infarction in diabetes mellitus. Arch Intern Med 2007;167:1353-9.

30 Lagerqvist B, Husted S, Kontny F, et al. 5-year outcomes in the FRISC-II randomised trial of an invasive versus a non-invasive strategy in non-ST-elevation acute coronary syndrome: a follow-up study. Lancet 2006;368:998-1004.

31 Wijns W, Kolh P, Danchin N, et al.; Guidelines on Myocardial Revascularization. The Task Force on Myocardial Revascularization of the European Society of Cardiology (ESC) and the European Association for Cardio-Thoracic Surgery (EACTS). Eur Heart J 2010;31:2501-55.

32 Rodriguez A, Bernardi V, Navia J, et al. Argentine randomized study: coronary angioplasty with stenting versus coronary bypass surgery in patients with multiple-vessel disease (ERACI II): 30-day and one-year follow-up results. J Am Coll Cardiol 2001;37:51-8.

33 Sigwart U, Stables RH, Booth J, et al. Coronary artery bypass surgery versus percutaneous coronary intervention with stent implantation in patients with multivessel coronary artery disease (the Stent or Surgery trial): a randomised controlled trial. Lancet 2002;360:965-70.

34 Abizaid A, Costa MA, Centemero M, et al. Clinical and economic impact of diabetes mellitus on percutaneous and surgical treatment of multivessel coronary disease patients: insights from the Arterial Revascularization Therapy Study (ARTS) trial. Circulation 2001;104:533-8.

35 Serruys PW, Ong ATL, van Herwerden LA, et al. Five-year outcomes after coronary stenting versus bypass surgery for the treatment of multivessel disease: the final analysis of the Arterial Revascularization Therapies Study (ARTS) randomized trial. J Am Coll Cardiol 2005;46:575-81.

36 Sedlis SP, Morrison DA, Lorin JD, et al. Percutaneous coronary intervention versus coronary bypass graft surgery for diabetic patients with unstable angina and risk factors for adverse outcomes with bypass: outcome of diabetic patients in the AWESOME randomized trial and registry. J Am Coll Cardiol 2002;40:1555-66.

37 Kapur A, Hall R, Malik I, et al. Randomized comparison of percutaneous coronary intervention with coronary artery bypass grafting in diabetic patients: 1 - year results of the CARDia (Coronary Artery Revascularization in Diabetes) Trial. J Am Coll Cardiol 2010;55:432-40.

38 Park SJ, Kim YH, Park DW, et al. Randomized trial of stents versus bypass surgery for left main coronary artery disease. N Engl J Med 2011;364:1718-27.

39 Farkouh ME, Domanski M, Sleeper LA, et al. Strategies for multivessel revascularization in patients with diabetes. N Engl J Med 2012;367:2375-84. 